OPEN ACCESS

Edited by:

Morenike Oluwatoyin Folayan, Obafemi Awolowo University, Nigeria

Reviewed by:

Cihad Dundar,

Ondokuz Mayıs University, Turkey

Laura Nabors,

University of Cincinnati, United States

*Correspondence:

Hui Fan

1577371399@qq.com

Specialty section:

This article was submitted to

Children and Health,

a section of the journal

Frontiers in Pediatrics

Received: 06 February 2021

Accepted: 26 March 2021

Published: 22 April 2021

Citation:

Fan $H$ and Zhang $X$ (2021) Prevalence of and Trends in the Co-Existence of Obesogenic Behaviors in Adolescents From 15 Countries.

Front. Pediatr. 9:664828. doi: $10.3389 /$ fped.2021.664828

\section{Prevalence of and Trends in the Co-Existence of Obesogenic Behaviors in Adolescents From 15 Countries}

\author{
Hui Fan ${ }^{1 *}$ and Xingyu Zhang ${ }^{2}$ \\ ${ }^{1}$ Department of Preventive Medicine, North Sichuan Medical College, Nanchong, China, ${ }^{2}$ Applied Biostatistics Laboratory, \\ University of Michigan School of Nursing, Ann Arbor, MI, United States
}

Background: The global epidemic of pediatric obesity is well-known, but data on coexistence of obesogenic behaviors are limited. We aim to report the prevalence of and trends in the co-existence of obesogenic behaviors in adolescents from 15 countries.

Methods: This study was based on the Global School-based Student Health Survey 2003-2017 and included 121,963 adolescents aged 12-15 years from 15 countries where at least 2 cross-sectional surveys were conducted. We used sampling weights and calculated the country-level prevalence of and trends in the co-existence of obesogenic behaviors (low fruit and vegetable intake, anxiety-induced insomnia, no physical activity, and sedentary behavior) during survey years. Pooled prevalence and trend estimates were calculated with random-effects models.

Results: Pooled prevalence of exposure $\geq 1, \geq 2$, and $\geq 3$ obesogenic behaviors was $88.2,44.9$, and $9.8 \%$ in the first survey and $88.4,46.4$, and $10.2 \%$ in the last survey, respectively. Plateauing, increasing, and decreasing trends in the co-existence of obesogenic behaviors were observed in different countries. Specifically, we identified a plateauing pooled trend in the exposure $\geq 1, \geq 2$, and $\geq 3$ obesogenic behaviors [odds ratios (95\% confidence intervals): $1.03(0.93,1.14), 1.05(0.97,1.13)$, and $1.06(0.95$, 1.18), respectively].

Conclusion: Trends in the prevalence of the co-existence of obesogenic behaviors varied significantly across different countries, but the prevalence remained high in most countries. These findings suggest the need for behavioral interventions to mitigate obesogenic behaviors in adolescents for overweight and obesity prevention.

Keywords: prevalence, trend, adolescents, obesogenic behaviors, co-existence

\section{INTRODUCTION}

Obesity in children and adolescents is a major risk factor for physical and psychosocial disorders throughout the lifespan (1-5). The prevalence of obesity in children and adolescents in recent years has been increasing in most countries, and has thus become a worldwide health concern $(1,2)$. During infectious disease pandemics, such as the COVID-19 pandemic, individuals with overweight/obesity who are infected are more likely to develop serious illnesses or die, compared with normal-weight individuals (6). 
The onset and development of obesity is a complicated process affected by a variety of biological and behavioral factors (7, 8). Compared with biological factors (e.g., genetics), behavioral factors (i.e., obesogenic behaviors), which include poor dietary habits, anxiety-induced insomnia, no physical activity, and sedentary behavior, are easily preventable, identifiable, and modifiable. Obesogenic behaviors also play an important role in the occurrence of population-wide obesity epidemics $(7,8)$, given that they are common in children and adolescents, according to global cross-sectional studies $(9,10)$. Behavioral habits established during childhood and adolescence tend to persist into and consolidate in adulthood $(11,12)$. Therefore, establishing healthy behavioral habits in childhood and adolescence is crucial to curb the epidemic of obesity and prevent associated disorders.

Single obesogenic behavior has been clarified well in adolescents $(9,10,13)$. However, to our best knowledge, data on prevalence of and trends in the co-existence of obesogenic behaviors in adolescents are limited. Such evidence is essential to develop and assess policies and programs to mitigate obesogenic behaviors. In this study, we aimed to assess the aforementioned issue based on the Global School-Based Student Health Survey (GSHS) 2003-2017.

\section{MATERIALS AND METHODS}

\section{Study Population}

The GSHS is a series of multi-country, repeated cross-sectional, and school-based surveys $(9,10)$. It was launched by the World Health Organization and US Centers for Disease and Control and Prevention to investigate health behaviors among schoolattending adolescents. It uses a standardized 2-stage, school-toclass probability sampling design in each participating country to obtain a nationally representative sample $(9,10)$. All students in the chosen class are invited to participate the survey. Data collection is conducted during a regular class period. Each country-specific GSHS during 2003-2017 was approved by the local government administration and an institutional review board or ethics committee. All participating students, parents, and/or school officials provided informed consent.

Publicly available data from GSHS can be found at https:// www.cdc.gov/gshs and https://www.who.int/ncds/surveillance/ gshs/factsheets/en/. From the available GSHS dataset, 34 countries that underwent repeated cross-sectional surveys were included in the present study. We excluded 1 country that lacked a nationally representative sample; 1 country with a different coding rule compared to other countries; 2 countries where the last surveys were not conducted after 2010; 11 countries that lacked data on fruit and vegetable intake, anxiety-induced insomnia, physical activity, sedentary behavior or weighted information; and 4 countries that lacked a sufficient sample size $(\geq 1,000)$ in any of at least 2 survey waves. Consequently, 177,201 school-attending adolescents from 15 countries were included in this study. We then excluded 46,029 adolescents whose age was missing or were $>15$ or $<12$ years old, and 9,209 adolescents

Abbreviations: GSHS, global school-based student health surveys; WHO, world health organization. for whom data on sex, food insecurity, fruit and vegetable intake, anxiety-induced insomnia, physical activity, sedentary behavior or weighted information were lacking. Eventually, 121,963 adolescents aged 12-15 years were included in the final analysis.

\section{Measures and Definition}

All students completed the survey questionnaire about obesogenic behaviors (14). Low vegetable and fruit intake was defined as consumption of fruit and vegetables $<5$ servings per day during the past 30 days (15). Participants, who were so worried about something that they could not sleep at night most of the time or always during the past 12 months, were considered to have anxiety-induced insomnia $(9,10)$. No physical activity was defined as no physical activity performance for at least 60 min on any day during the past 7 days $(9,10)$. Participants, who spend $\geq 3 \mathrm{~h}$ /day during a typical or usual day in sitting and watching television, playing computer games, talking with friends, or doing other sitting activities after excluding time at school or doing homework, were considered to have sedentary behaviors $(9,10)$.

The GSHS asked participants for their obesogenic behaviors (low fruit and vegetable intake, anxiety-induced insomnia, no physical activity, and sedentary behavior); a value of " 1 " or " 0 " was assigned to participants who had or did not have each type of obesogenic behavior, respectively. Consequently, the number of obesogenic behaviors for each participant ranged from 0 to 4 , with each type of obesogenic behavior worth 1 point.

Data on sex, age, and food insecurity were also collected. Food insecurity was evaluated based on the question "How often did you go hungry because there was not enough food in your home during the past 30 days?" The response options were "never," "rarely/sometimes," and "most of the time/always $(9,10)$."

\section{Statistical Analysis}

Sampling weights were used to account for the complex sampling design (14). We calculated the country-specific prevalence of each type of obesogenic behavior in different survey years. We also evaluated the country-level prevalence of exposure $\geq 1, \geq 2$, and $\geq 3$ obesogenic behaviors. We used the logistic regression analyses to assess trends in the prevalence of exposure $\geq 1$ (reference: $<1$ ), $\geq 2$ (reference: $<2$ ), and $\geq 3$ (reference: $<3$ ) obesogenic behaviors across the survey years after adjustment for sex, age, and food insecurity. For example, to assess the trends in the prevalence of exposure $\geq 2$ obesogenic behaviors, we assigned the outcome value of " 1 " or " 0 " to participants who had $\geq 2$ or had $<2$ obesogenic behaviors, respectively. We computed the pooled prevalence in the first and last surveys by the corresponding country-specific prevalence using a random-effects model. To assess the pooled trend in the prevalence of exposure $\geq 1, \geq 2$, and $\geq 3$ obesogenic behaviors across the survey years, we also used a random-effects model to calculate the pooled estimates stratified by WHO region (Americas, Eastern Mediterranean, Western Pacific, African, and Southeast Asia), World Bank income level (high income, upper-middle income, and lower-middle income), and number of surveys ( 2 and $\geq 3$ ), based on the corresponding 
TABLE 1 | Survey characteristics in 15 countries.

\begin{tabular}{|c|c|c|c|c|c|c|c|}
\hline Country & Region & Income & Survey year & Response rate, \% & Available sample size & Mean age, years & Boys, \% \\
\hline \multirow[t]{2}{*}{ Argentina } & Americas & Upper middle income & 2007 & 94.2 & 1,448 & 14.1 & 45.9 \\
\hline & & & 2012 & 92.4 & 19,883 & 13.9 & 47.6 \\
\hline \multirow[t]{2}{*}{ Fiji } & Western Pacific & Upper middle income & 2010 & 94.0 & 1,405 & 14.0 & 47.6 \\
\hline & & & 2016 & 88.3 & 1,357 & 14.4 & 48.1 \\
\hline \multirow[t]{2}{*}{ Guatemala } & Americas & Upper middle income & 2009 & 94.4 & 4,244 & 13.9 & 52.2 \\
\hline & & & 2015 & 85.9 & 3,101 & 13.9 & 50.5 \\
\hline \multirow[t]{2}{*}{ Indonesia } & South-East Asia & Upper middle income & 2007 & 96.9 & 2,928 & 13.8 & 49.2 \\
\hline & & & 2015 & 95.2 & 8,384 & 13.5 & 49.1 \\
\hline \multirow[t]{2}{*}{ Kuwait } & Eastern Mediterranean & High income & 2011 & 95.0 & 2,183 & 14.1 & 49.5 \\
\hline & & & 2015 & 85.9 & 1,748 & 14.1 & 50.1 \\
\hline \multirow[t]{2}{*}{ Lebanon } & Eastern Mediterranean & Upper middle income & 2011 & 93.0 & 1,843 & 13.7 & 46.5 \\
\hline & & & 2017 & 89.6 & 3,000 & 13.6 & 46.0 \\
\hline \multirow[t]{3}{*}{ Morocco } & Eastern Mediterranean & Lower middle income & 2006 & 92.3 & 1,834 & 14.0 & 52.3 \\
\hline & & & 2010 & 91.7 & 2,206 & 13.7 & 53.3 \\
\hline & & & 2016 & 88.4 & 3,513 & 13.6 & 50.5 \\
\hline \multirow[t]{2}{*}{ Myanmar } & South-East Asia & Lower middle income & 2007 & 98.4 & 2,191 & 13.6 & 49.5 \\
\hline & & & 2016 & 95.9 & 2,146 & 13.6 & 46.4 \\
\hline \multirow[t]{4}{*}{ Philippines } & Western Pacific & Lower middle income & 2003 & 92.8 & 3,896 & 14.1 & 40.1 \\
\hline & & & 2007 & 94.6 & 3,296 & 14.3 & 44.5 \\
\hline & & & 2011 & 93.5 & 3,596 & 13.9 & 47.8 \\
\hline & & & 2015 & 96.9 & 5,971 & 13.9 & 47.9 \\
\hline \multirow[t]{2}{*}{ Seychelles } & African & High income & 2007 & 88.7 & 1,024 & 13.6 & 47.9 \\
\hline & & & 2015 & 90.4 & 1,864 & 13.5 & 47.0 \\
\hline \multirow[t]{2}{*}{ Sri Lanka } & South-East Asia & Lower middle income & 2008 & 96.8 & 2,423 & 13.7 & 49.6 \\
\hline & & & 2016 & 95.8 & 2,159 & 14.0 & 48.8 \\
\hline \multirow[t]{2}{*}{ Thailand } & South-East Asia & Upper middle income & 2008 & 97.3 & 2,603 & 13.6 & 47.7 \\
\hline & & & 2015 & 92.9 & 3,839 & 13.7 & 48.4 \\
\hline \multirow[t]{2}{*}{ Tonga } & Western Pacific & Upper middle income & 2010 & 94.8 & 1,844 & 14.1 & 50.3 \\
\hline & & & 2017 & 94.1 & 1,945 & 13.6 & 51.3 \\
\hline \multirow[t]{3}{*}{ Trinidad and Tobago } & Americas & High income & 2007 & 90.6 & 2,219 & 13.8 & 48.3 \\
\hline & & & 2011 & 91.2 & 2,154 & 13.6 & 49.3 \\
\hline & & & 2017 & 90.1 & 2,489 & 13.6 & 47.3 \\
\hline \multirow[t]{3}{*}{ United Arab Emirates } & Eastern Mediterranean & High income & 2005 & 92.4 & 11,844 & 13.7 & 47.6 \\
\hline & & & 2010 & 93.1 & 2,144 & 14.0 & 38.3 \\
\hline & & & 2016 & 93.3 & 3,239 & 13.9 & 47.0 \\
\hline
\end{tabular}

country-specific estimated odds ratio (OR) and $95 \%$ confidence interval (95\% CI).

We used SAS version 9.4 (SAS Institute, Cary, NC, USA) and STATA version 11.0 (Stata Corporation, College Station, TX, USA) to perform the statistical analyses, and considered $P$-values of $<0.05$ as statistically significant.

\section{RESULTS}

This study included 121,963 adolescents aged 12-15 years from 15 countries. Table 1 summarizes the country-level survey characteristics during the survey years (2003-2017). The 15 participating countries were classified into 5 WHO regions (Southeast Asia: 4; Eastern Mediterranean: 4; Western Pacific:
3; Americas: 3; African: 1) and 3 World Bank income levels (high income: 4; upper-middle income: 7; lower-middle income: 4). Further, 4 and 11 countries had $\geq 3$ and two survey waves, respectively. The GSHS in the 15 countries were conducted in different survey years from 2003 to 2017. The response rates for all country-level surveys were $>85 \%$. The country-level available sample sizes in the surveys varied, ranging from 1,024 in Seychelles in 2007 to 19,883 in Argentina in 2012.

Table 2 shows the prevalence of each type of obesogenic behavior across the 15 countries in different survey years. The prevalence of low fruit and vegetable intake, anxietyinduced insomnia, no physical activity, and sedentary behavior varied widely, ranging from 52.6\% in Seychelles in 2007 to 89.8\% in Myanmar in 2016, from 1.8\% in Myanmar in 2007 to 19.6\% in Kuwait in 2011, from 14.1\% in Argentina in 2012 to 
45.4\% in Philippines in 2007, and from 9.7\% in Myanmar in 2007 to $63.3 \%$ in Kuwait in 2015, respectively. The respective pooled prevalence of these 4 obesogenic behaviors was $72.0,10.5,24.8$, and $36.2 \%$ in the first survey and $73.1,9.9,25.7$, and $37.2 \%$ in the last survey,

Table 3 presents the country-level prevalence of the coexistence of obesogenic behaviors and related trends across the survey years. The prevalence of exposure $\geq 1, \geq 2$, and

TABLE 2 | Prevalence of each type of obesogenic behaviors across 15 countries in different survey year.

\begin{tabular}{|c|c|c|c|c|c|}
\hline Country & $\begin{array}{c}\text { Survey } \\
\text { year }\end{array}$ & $\begin{array}{l}\text { Low fruit } \\
\text { and } \\
\text { vegetable } \\
\text { intake, } \%\end{array}$ & $\begin{array}{c}\text { Anxiety- } \\
\text { induced } \\
\text { sleep } \\
\text { problems, \% }\end{array}$ & $\begin{array}{c}\text { No physical } \\
\text { activity, \% }\end{array}$ & $\begin{array}{c}\text { Sedentary } \\
\text { behaviors, \% }\end{array}$ \\
\hline \multirow[t]{2}{*}{ Argentina } & 2007 & 85.8 & 10.9 & 22.9 & 49.5 \\
\hline & 2012 & 82.4 & 8.4 & 14.1 & 50.3 \\
\hline \multirow[t]{2}{*}{ Fiji } & 2010 & 60.6 & 14.5 & 26.4 & 27.5 \\
\hline & 2016 & 63.4 & 11.2 & 28.5 & 28.1 \\
\hline \multirow[t]{2}{*}{ Guatemala } & 2009 & 73.4 & 6.9 & 19.3 & 25.3 \\
\hline & 2015 & 70.3 & 6.3 & 30.4 & 22.9 \\
\hline \multirow[t]{2}{*}{ Indonesia } & 2007 & 75.2 & 7.5 & 14.7 & 33.8 \\
\hline & 2015 & 75.3 & 4.3 & 34.2 & 24.4 \\
\hline \multirow[t]{2}{*}{ Kuwait } & 2011 & 77.7 & 19.6 & 28.0 & 53.5 \\
\hline & 2015 & 81.1 & 17.8 & 20.5 & 63.3 \\
\hline \multirow[t]{2}{*}{ Lebanon } & 2011 & 71.7 & 10.5 & 16.3 & 47.2 \\
\hline & 2017 & 75.7 & 12.0 & 22.1 & 40.2 \\
\hline \multirow[t]{3}{*}{ Morocco } & 2006 & 62.9 & 13.4 & 16.7 & 30.1 \\
\hline & 2010 & 52.9 & 14.1 & 22.2 & 25.9 \\
\hline & 2016 & 64.3 & 14.0 & 23.7 & 26.3 \\
\hline \multirow[t]{2}{*}{ Myanmar } & 2007 & 83.6 & 1.8 & 31.1 & 9.7 \\
\hline & 2016 & 89.8 & 3.4 & 29.4 & 15.7 \\
\hline \multirow[t]{4}{*}{ Philippines } & 2003 & 75.1 & 13.6 & 45.0 & 28.3 \\
\hline & 2007 & 78.6 & 12.1 & 45.4 & 29.5 \\
\hline & 2011 & 74.2 & 10.4 & 42.5 & 32.5 \\
\hline & 2015 & 74.5 & 10.4 & 44.7 & 30.8 \\
\hline \multirow[t]{2}{*}{ Seychelles } & 2007 & 52.6 & 11.9 & 27.1 & 51.1 \\
\hline & 2015 & 59.3 & 10.5 & 30.8 & 49.4 \\
\hline \multirow[t]{2}{*}{ Sri Lanka } & 2008 & 77.2 & 4.3 & 17.7 & 33.1 \\
\hline & 2016 & 75.9 & 3.8 & 15.1 & 35.1 \\
\hline \multirow[t]{2}{*}{ Thailand } & 2008 & 66.1 & 6.6 & 19.1 & 37.7 \\
\hline & 2015 & 70.0 & 8.0 & 23.2 & 50.8 \\
\hline \multirow[t]{2}{*}{ Tonga } & 2010 & 61.0 & 15.5 & 32.5 & 29.2 \\
\hline & 2017 & 54.8 & 13.4 & 24.4 & 20.4 \\
\hline \multirow{3}{*}{$\begin{array}{l}\text { Trinidad and } \\
\text { Tobago }\end{array}$} & 2007 & 76.4 & 9.2 & 32.8 & 49.2 \\
\hline & 2011 & 83.9 & 7.2 & 28.0 & 44.0 \\
\hline & 2017 & 81.8 & 11.7 & 26.8 & 46.3 \\
\hline \multirow{3}{*}{$\begin{array}{l}\text { United Arab } \\
\text { Emirates }\end{array}$} & 2005 & 81.3 & 12.6 & 24.9 & 39.0 \\
\hline & 2010 & 83.0 & 15.1 & 19.9 & 51.2 \\
\hline & 2016 & 76.5 & 14.3 & 19.0 & 54.6 \\
\hline \multirow[t]{2}{*}{$\begin{array}{l}\text { Pooled } \\
\text { estimate }\end{array}$} & $\begin{array}{l}\text { First } \\
\text { survey }\end{array}$ & 72.0 & 10.5 & 24.8 & 36.2 \\
\hline & $\begin{array}{l}\text { Last } \\
\text { survey }\end{array}$ & 73.1 & 9.9 & 25.7 & 37.2 \\
\hline
\end{tabular}

$\geq 3$ obesogenic behaviors differed substantially, ranging from $74.9 \%$ in Tonga in 2017 to $95.0 \%$ in Argentina in 2007, from $31.3 \%$ in Morocco in 2010 and in Tonga in 2017 to $66.0 \%$ in Kuwait in 2015, and from 2.7\% in Myanmar in 2007 to 22.8\% in Kuwait in 2011, respectively. Plateauing, increasing, and decreasing trends were observed in the prevalence of exposure $\geq 2$ obesogenic behaviors in 10,3 , and 2 countries, respectively $\left(P_{\mathrm{s}}>0.05\right.$ for 10 countries; $P_{\mathrm{s}}<0.05$ for 3 and 2 countries). Notably, the prevalence of the co-existence of $\geq 2$ obesogenic behaviors in all of the 15 countries in the latest survey year remained high (>30\%), regardless of the different country-level trends. Furthermore, plateauing, increasing, and decreasing trends were identified in the prevalence of $\geq 3$ obesogenic behaviors in 8,5 , and 2 countries, respectively $\left(P_{\mathrm{s}}>0.05\right.$ for 8 countries; $P_{\mathrm{s}}<0.05$ for 5 and 2 countries). In 4 of the 8 countries with a plateauing trend (Trinidad and Tobago, Kuwait, United Arab Emirates, and the Philippines) and 3 of the 5 countries with an increasing trend (Lebanon, Seychelles, and Thailand), the prevalence of $\geq 3$ obesogenic behaviors in the latest survey year was $>10 \%$. Supplementary Tables 1 and 2 describe the country-level prevalence and trend among boys and girls, respectively. The difference in the trend among boys and girls can be noted in Indonesia, Kuwait, Lebanon, Seychelles, and United Arab Emirates.

Table 4 reports the pooled estimates of the prevalence of and trends in the co-existence of obesogenic behaviors from the 15 countries. The pooled prevalence of $\geq 1, \geq 2$, and $\geq 3$ obesogenic behaviors was $88.2,44.9$, and $9.8 \%$ in the first survey and 88.4 , 46.4 , and $10.2 \%$ in the last survey, respectively. A plateauing pooled trend was observed in the prevalence of $\geq 1, \geq 2$, and $\geq 3$ obesogenic behaviors [OR (95\% CI): $1.03(0.93,1.14), 1.05$ (0.97, $1.13)$, and $1.06(0.95,1.18)$, respectively].

\section{DISCUSSION}

This study indicated that the prevalence of exposure $\geq 2$ and $\geq 3$ obesogenic behaviors varied widely across the 15 countries and continued to be at high levels in most countries. We also founded the plateauing, increasing, and decreasing trends in the prevalence of exposure $\geq 2$ and $\geq 3$ obesogenic behaviors within different countries.

The effects of obesogenic behaviors on adiposity are well-known. For example, low consumption of fruits and vegetables is known to promote pediatric obesity due to the displacement of fiber- and micronutrient-rich fruits and vegetables with energy-dense foods (16). A short sleep duration is believed to play an important role in the onset and development of obesity through changes in endocrinal, neurological, and behavioral mechanisms (17). Low levels of physical activity, which reduce energy expenditure and promote appetite, are also implicated in obesity (18). Sedentary behavior is reported to contribute to obesity via snacking, decreasing energy expenditure, and increasing abdominal fat (19).

Previous cross-sectional studies based on GSHS dataset and publications from other data sources have reported a high 
TABLE 3 | Prevalence of the co-existence of obesogenic behaviors and their trends in 15 countries across survey years.

\begin{tabular}{|c|c|c|c|c|c|c|c|c|c|c|}
\hline \multirow[t]{2}{*}{ Country } & \multirow[t]{2}{*}{ Survey year } & \multicolumn{3}{|c|}{ Number of obesogenic behaviors $\geq 1$} & \multicolumn{3}{|c|}{ Number of obesogenic behaviors $\geq 2$} & \multicolumn{3}{|c|}{ Number of obesogenic behaviors $\geq 3$} \\
\hline & & Prevalence, $\%$ & OR $(95 \% \mathrm{Cl})^{*}$ & $\boldsymbol{P}$ & Prevalence, $\%$ & OR $(95 \% \mathrm{Cl})^{*}$ & $\boldsymbol{P}$ & Prevalence, \% & OR $(95 \% \mathrm{Cl})^{\star}$ & $\boldsymbol{P}$ \\
\hline \multirow[t]{2}{*}{ Argentina } & & & $0.73(0.49,1.10)$ & 0.134 & & $0.77(0.61,0.96)$ & 0.023 & & $0.70(0.60,0.80)$ & ) $<0.001$ \\
\hline & 2012 & 93.1 & & & 51.8 & & & 9.7 & & \\
\hline Fiji & & & $0.95(0.73,1.24)$ & 0.700 & & $1.08(0.90,1.30)$ & 0.396 & & $1.05(0.79,1.40)$ & 0.736 \\
\hline \multirow[t]{3}{*}{ Guatemala } & & & $1.02(0.89,1.16)$ & 0.823 & & $1.18(0.96,1.45)$ & 0.117 & & $1.06(0.72,1.58)$ & 0.754 \\
\hline & 2009 & 84.7 & & & 34.4 & & & 5.5 & & \\
\hline & 2015 & 85.0 & & & 38.4 & & & 6.0 & & \\
\hline \multirow[t]{2}{*}{ Indonesia } & & & $1.09(0.90,1.32)$ & 0.380 & & $1.33(1.08,1.63)$ & 0.007 & & $1.09(0.77,1.55)$ & 0.635 \\
\hline & 2007 & 88.2 & & & 36.6 & & & 6.1 & & \\
\hline \multirow[t]{3}{*}{ Lebanon } & & & $1.03(0.82,1.29)$ & 0.802 & & $1.13(0.97,1.32)$ & 0.120 & & $1.38(1.09,1.74)$ & 0.010 \\
\hline & 2011 & 89.3 & & & 45.8 & & & 9.4 & & \\
\hline & 2017 & 89.2 & & & 47.8 & & & 12.0 & & \\
\hline \multirow[t]{4}{*}{ Morocco } & & & $1.14(1.03,1.26)$ & 0.015 & & $1.06(0.99,1.13)$ & 0.101 & & $1.31(1.13,1.50)$ & ) $<0.001$ \\
\hline & 2006 & 81.5 & & & 35.5 & & & 5.7 & & \\
\hline & 2010 & 77.4 & & & 31.3 & & & 6.0 & & \\
\hline & 2016 & 83.5 & & & 36.0 & & & 8.3 & & \\
\hline \multirow[t]{3}{*}{ Myanmar } & & & $1.71(1.18,2.49)$ & 0.006 & & $1.19(0.97,1.46)$ & 0.096 & & $2.38(1.54,3.67)$ & ) $<0.001$ \\
\hline & 2007 & 88.7 & & & 34.7 & & & 2.7 & & \\
\hline & 2016 & 92.9 & & & 38.8 & & & 6.1 & & \\
\hline & 2015 & 87.2 & & & 48.7 & & & 13.0 & & \\
\hline \multirow[t]{3}{*}{ Sri Lanka } & & & $0.82(0.65,1.04)$ & 0.098 & & $0.96(0.80,1.15)$ & 0.638 & & $0.97(0.72,1.30)$ & ) 0.817 \\
\hline & 2008 & 89.0 & & & 37.6 & & & 5.6 & & \\
\hline & 2016 & 87.2 & & & 37.0 & & & 5.5 & & \\
\hline \multirow[t]{3}{*}{ Thailand } & & & $1.70(1.28,2.26)$ & 0.001 & & $1.56(1.22,2.00)$ & $<0.001$ & & $1.51(1.13,2.04)$ & 0.007 \\
\hline & 2008 & 81.9 & & & 39.0 & & & 8.2 & & \\
\hline & 2015 & 88.7 & & & 50.3 & & & 12.1 & & \\
\hline \multirow[t]{3}{*}{ Tonga } & & & $0.55(0.44,0.68)$ & $<0.001$ & & $0.63(0.54,0.74)$ & $<0.001$ & & $0.68(0.54,0.86)$ & 0.001 \\
\hline & 2010 & 84.7 & & & 43.4 & & & 9.5 & & \\
\hline & 2017 & 74.9 & & & 31.3 & & & 6.4 & & \\
\hline Trinidad and Tobago & & & $1.10(0.95,1.27)$ & 0.219 & & $0.98(0.89,1.07)$ & 0.665 & & $0.98(0.87,1.10)$ & 0.688 \\
\hline & 2007 & 92.2 & & & 57.9 & & & 15.7 & & \\
\hline & 2011 & 94.5 & & & 54.4 & & & 13.1 & & \\
\hline & 2017 & 93.0 & & & 56.7 & & & 15.0 & & \\
\hline United Arab Emirates & & & $0.90(0.79,1.02)$ & 0.097 & & $1.06(0.99,1.13)$ & 0.114 & & $1.05(0.97,1.15)$ & 0.231 \\
\hline & 2005 & 91.8 & & & 51.3 & & & 13.3 & & \\
\hline & 2010 & 93.8 & & & 57.9 & & & 15.8 & & \\
\hline & 2016 & 91.1 & & & 56.0 & & & 15.6 & & \\
\hline
\end{tabular}

*Adjusting for sex, age, food insecurity; Cl, confidence interval; OR, odds ratio. 


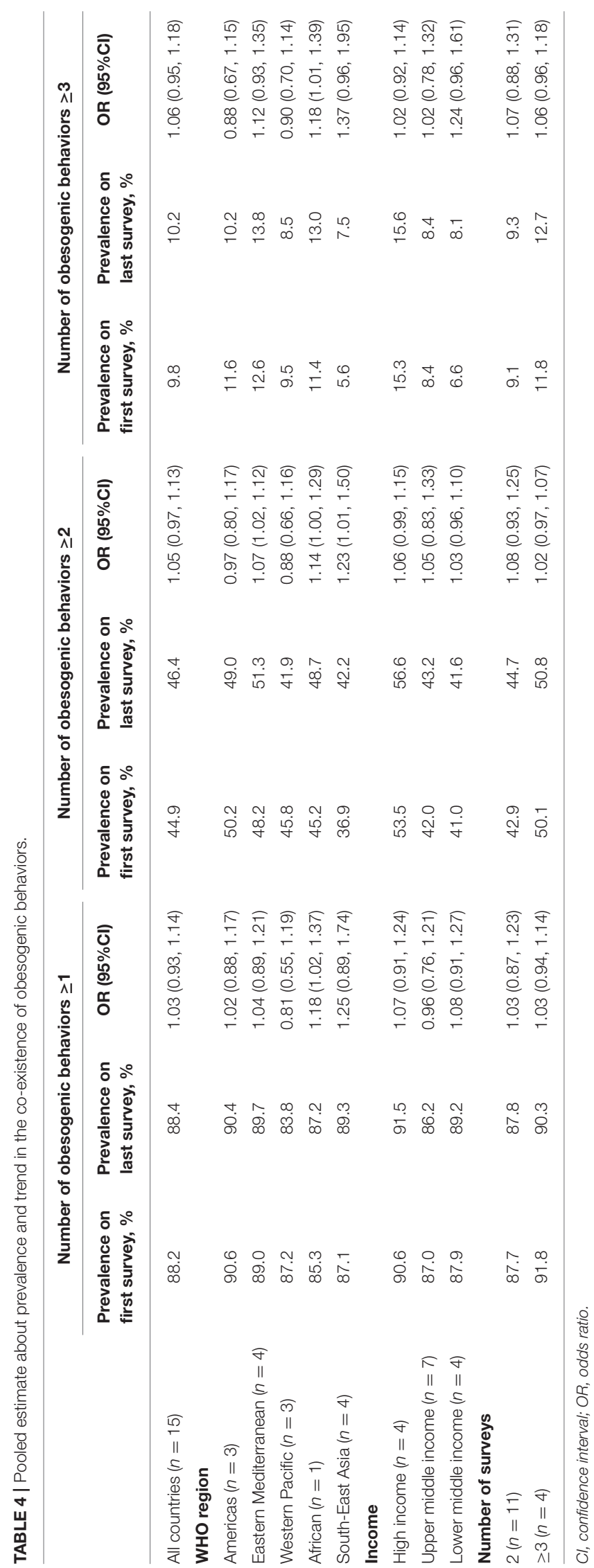

prevalence of single obesogenic behaviors (e.g., low fruit and vegetable intake, insufficient physical activity, and sedentary behavior), which is consistent with our results (9, 10, 19-22). However, our findings further reveal that the prevalence of the co-existence of $\geq 2$ and $\geq 3$ obesogenic behaviors varied widely across the included countries during the survey years (20032017), but remained high in most countries regardless of survey waves. Further, compared with previous studies that evaluated trends in single obesogenic behaviors $(13,23,24)$, the added advantage of this study is that it included only those countries that had at least 2 GSHS waves (15 countries in total) and could thus demonstrate dynamic country-level changes in the co-occurrence of obesogenic behaviors. Our study also revealed plateauing, increasing, and decreasing trends in the prevalence of the co-existence of $\geq 2$ and $\geq 3$ obesogenic behaviors across different countries. These results are partly consistent with those of previous studies that observed trends in the prevalence of insufficient physical activity, low fruit and vegetable intake, and sedentary behavior $(13,23,24)$.

Our finding of the wide variation in the co-occurrence of $\geq 2$ and with the $\geq 3$ obesogenic behaviors and the corresponding trends across countries might be attributable to country-level variations in environmental, economic, social, policy-related, and other factors $(7,8,13,25-29)$. For example, the epidemics of obesogenic behaviors are partly driven by changes in the food environment (e.g., availability of unhealthy processed foods), economic progress (e.g., industrialization, urbanization, marketization, and globalization), and social transformations (e.g., technological advances such as the informatization and introduction of activity-saving technologies) (26-29). With regard to policy-related factors, some countries that recognize the urgent need to tackle childhood obesity have implemented policies to mitigate obesogenic behaviors, with noticeable effects $(1,2,13,26,27,30)$. This explains the decreasing trend in the co-existence of obesogenic behaviors we observed in some countries.

Multilevel factors, such as individual, family, community, and societal factors, contribute to the onset and development of childhood obesity (31). Notably, family, community, and societal factors tend to contribute to pediatric obesity through individuallevel obesogenic behaviors (31). Genetic predisposition, another individual-level factor, is partly responsible for obesity in childhood, but is believed to play a minor role relative to behavioral factors (18). Taken together, these findings suggest that the prevention of and interventions to mitigate obesogenic behaviors are crucial in curbing the epidemic of childhood obesity. Our findings have important implications for mitigating obesogenic behaviors and related-obesity in adolescents. First, the results suggest that country-level prevention and intervention policies for obesogenic behaviors should be established and implemented in countries where relevant policies are scarce. Second, in the remaining countries where the prevalence has increased or remained high, it is necessary to reconsider the effectiveness of existing policies. Third, obesogenic behavior prevention and intervention policies should be comprehensive, such that they target poor dietary habits, sleep disorders, low/no physical activity, and sedentary behavior $(7,8,26)$. Finally, 
sex differences in the trend in the prevalence of the coexistence of obesogenic behaviors in some countries should be noted for policy makers. The reason for these results needs to be clarified.

The main strengths of our study are the nationally representative samples, rigorous and standardized data collection, the practical nature of this research and its global scale. However, some limitations need to be acknowledged. First, this study did not include countries from Europe or low-income countries, included only 1 country from the African region, and excluded 11 countries without complete data and 4 countries without the sufficient sample size $(\geq 1,000)$ during any of at least 2 survey waves, which limits the generalizability of our findings. Second, the survey years, sample sizes, and survey numbers differed between the participating countries, which could have affected our results. Third, our study included only school-attending adolescents aged 12-15 years. A future study on trends in obesogenic behaviors should focus on younger children or adolescents who do not attend school. Fourth, there is no data about environmental factors that affect obesogenic behavior in the present study. Finally, the data collected were self-reported, which may have introduced some bias.

In conclusion, the results of this study indicate that the prevalence of the co-existence of obesogenic behaviors remained high in most of the included countries during 2003-2017, even though the corresponding trends varied widely across the countries. This finding suggests that most countries need to implement interventions to mitigate obesogenic behaviors in adolescents and prevent overweight and obesity.

\section{DATA AVAILABILITY STATEMENT}

The raw data supporting the conclusions of this article will be made available by the authors, without undue reservation.

\section{REFERENCES}

1. NCD Risk Factor Collaboration (NCD-RisC). Worldwide trends in bodymass index, underweight, overweight, and obesity from 1975 to 2016: a pooled analysis of 2416 population-based measurement studies in 128.9 million children, adolescents, and adults. Lancet. (2017) 390:2627-42. doi: 10.1016/S0140-6736(17)32129-3

2. NCD Risk Factor Collaboration (NCD-RisC). Height and body-mass index trajectories of school-aged children and adolescents from 1985 to 2019 in 200 countries and territories: a pooled analysis of 2181 populationbased studies with 65 million participants. Lancet. (2020) 396:1511-24. doi: 10.1016/S0140-6736(20)31859-6

3. Skinner AC, Perrin EM, Moss LA, Skelton JA. Cardiometabolic risks and severity of obesity in children and young adults. N Engl J Med. (2015) 373:1307-17. doi: 10.1056/NEJMoa1502821

4. Franks PW, Hanson RL, Knowler WC, Sievers ML, Bennett PH, Looker HC. Childhood obesity, other cardiovascular risk factors, and premature death. $N$ Engl J Med. (2010) 362:485-93. doi: 10.1056/NEJMoa0904130

5. Sawyer MG, Harchak T, Wake M, Lynch J. Four-year prospective study of BMI and mental health problems in young children. Pediatrics. (2011) 128:677-84. doi: 10.1542/peds.2010-3132

\section{ETHICS STATEMENT}

The studies involving human participants were reviewed and approved by the local government administration and an institutional review board or ethics committee. Written informed consent to participate in this study was provided by the participants' legal guardian/next of kin.

\section{AUTHOR CONTRIBUTIONS}

HF conceptualized and designed the study, carried out the initial analyses, drafted the initial manuscript, and reviewed and revised the manuscript. XZ critically reviewed and revised the manuscript. All authors contributed to the article and approved the submitted version.

\section{FUNDING}

This study was supported by the PhD Funding Program of North Sichuan Medical College (CBY18-QD02), Funding Program of Primary Health Development Research Center of Sichuan Province (SWFZ20-Q-045), and 13th FiveYear Plan of Social Science Research in Nanchong in 2020 (NC2020C068).

\section{ACKNOWLEDGMENTS}

We thank the WHO and US Centers for Disease Control for sharing the GSHS datasets.

\section{SUPPLEMENTARY MATERIAL}

The Supplementary Material for this article can be found online at: https://www.frontiersin.org/articles/10.3389/fped. 2021.664828/full\#supplementary-material

6. Yadav R, Aggarwal S, Singh A. SARS CoV-2-host dynamics: increased risk of adverse outcomes of COVID-19 in obesity. Diabetes Metab Syndr. (2020) 14:1355-60. doi: 10.1016/j.dsx.2020.07.030

7. Kumar S, Kelly AS. Review of childhood obesity: from epidemiology, etiology, and comorbidities to clinical assessment and treatment. Mayo Clin Proc. (2017) 92:251-65. doi: 10.1016/j.mayocp.2016. 09.017

8. Styne DM, Arslanian SA, Connor EL, Farooqi IS, Murad MH, Silverstein JH, et al. Pediatric obesity-assessment, treatment, and prevention: an endocrine society clinical practice guideline. J Clin Endocrinol Metab. (2017) 102:70957. doi: 10.1210/jc.2016-2573

9. Smith L, Jacob L, Shin JI, Tully MA, Pizzol D, López-Sánchez GF, et al. Bullying victimization and obesogenic behaviour among adolescents aged 12 to 15 years from 54 low- and middle-income countries. Pediatr Obes. (2021) 16:e12700. doi: 10.1111/ijpo.12700

10. Smith L, Jacob L, Grabovac I, López-Sánchez GF, Yang L, Carvalho $\mathrm{AF}$, et al. Violence and obesogenic behavior among adolescents aged 12-15 years from 62 countries: a global perspective. Prev Med. (2020) 137:106123. doi: 10.1016/j.ypmed.2020.106123

11. Kohl HW 3rd, Hobbs KE. Development of physical activity behaviors among children and adolescents. Pediatrics. (1998) 101:549-54. 
12. Lien N, Lytle LA, Klepp KI. Stability in consumption of fruit, vegetables, and sugary foods in a cohort from age 14 to age 21. Prev Med. (2001) 33:217-26. doi: 10.1006/pmed.2001.0874

13. Guthold R, Stevens GA, Riley LM, Bull FC. Global trends in insufficient physical activity among adolescents: a pooled analysis of 298 population-based surveys with 1.6 million participants. Lancet Child Adolesc Health. (2020) 4:23-35. doi: 10.1016/S2352-4642(19)30323-2

14. World Health Organization, US Centers for Disease Control and Prevention. (2013). Available online at: https://www.cdc.gov/gshs/background/pdf/gshsdata-users-guide.pdf (accessed November 17, 2020).

15. Fan $\mathrm{H}$, Zhang X. Clustering of poor dietary habits among adolescents aged 12 to 15 years in 52 low-income and middle-income countries. Int J Environ Res Public Health. (2020) 17:6806. doi: 10.3390/ijerph17186806

16. Fletcher S, Wright C, Jones A, Parkinson K, Adamson A. Tracking of toddler fruit and vegetable preferences to intake and adiposity later in childhood. Matern Child Nutr. (2017) 13:e12290. doi: 10.1111/mcn.12290

17. Chaput JP. Sleep patterns, diet quality and energy balance. Physiol Behav. (2014) 134:86-91. doi: 10.1016/j.physbeh.2013.09.006

18. Hills AP, Andersen LB, Byrne NM. Physical activity and obesity in children. Br J Sports Med. (2011) 45:866-70. doi: 10.1136/bjsports-2011-090199

19. Ashdown-Franks G, Vancampfort D, Firth J, Veronese N, Jackson SE, Smith L, et al. Leisure-Time sedentary behavior and obesity among 116,762 adolescents aged 12-15 years from 41 low- and middle-income countries. Obesity. (2019) 27:830-36. doi: 10.1002/oby.22424

20. Roman-Viñas B, Chaput JP, Katzmarzyk PT, Fogelholm M, Lambert EV, Maher C, et al. ISCOLE Research Group. Proportion of children meeting recommendations for 24-hour movement guidelines and associations with adiposity in a 12-country study. Int J Behav Nutr Phys Act. (2016) 13:123. doi: 10.1186/s12966-016-0449-8

21. Cooper AR, Goodman A, Page AS, Sherar LB, Esliger DW, van Sluijs EM, et al. Objectively measured physical activity and sedentary time in youth: the international children's accelerometry database (ICAD). Int J Behav Nutr Phys Act. (2015) 12:113. doi: 10.1186/s12966-015-0274-5

22. Evans CE, Christian MS, Cleghorn CL, Greenwood DC, Cade JE. Systematic review and meta-analysis of school-based interventions to improve daily fruit and vegetable intake in children aged 5 to 12 y. Am J Clin Nutr. (2012) 96:889-901. doi: 10.3945/ajcn.111.030270

23. Vereecken C, Pedersen TP, Ojala K, et al. Fruit and vegetable consumption trends among adolescents from 2002 to 2010 in 33 countries. Eur J Public Health. (2015) 25(Suppl. 2):16-9. doi: 10.1093/eurpub/ckv012
24. Yang L, Cao C, Kantor ED, Nguyen LH, Zheng X, Park Y, et al. Trends in sedentary behavior among the US population, 2001-2016. JAMA. (2019) 321:1587-97. doi: 10.1001/jama.2019.3636

25. de Jong E, Visscher TL, HiraSing RA, Seidell JC, Renders CM. Home environmental determinants of children's fruit and vegetable consumption across different SES backgrounds. Pediatr Obes. (2015) 10:134-40. doi: 10.1111/ijpo.243

26. Kumanyika S, Dietz WH. Solving population-wide obesity progress and future prospects. N Engl J Med. (2020) 383:2197200. doi: 10.1056/NEJMp2029646

27. Hawkes C, Ruel MT, Salm L, Sinclair B, Branca F. Double-duty actions: seizing programme and policy opportunities to address malnutrition in all its forms. Lancet. (2020) 395:142-55. doi: 10.1016/S0140-6736(19) 32506-1

28. Popkin BM, Corvalan C, Grummer-Strawn LM. Dynamics of the double burden of malnutrition and the changing nutrition reality. Lancet. (2020) 395:65-74. doi: 10.1016/S0140-6736(19)32497-3

29. Wu Y, Benjamin EJ, MacMahon S. Prevention and control of cardiovascular disease in the rapidly changing economy of china. Circulation. (2016) 133:2545-60. doi: 10.1161/CIRCULATIONAHA.115. 008728

30. Cheng G, Yang F, Xiong F, Zhao L, Zhang L, Wang Y. Comparison of nutrition education policies and programs for children in China and other selected developed countries. Glob Health J. (2020) 4:728. doi: 10.1016/j.glohj.2020.08.002

31. Davison KK, Birch LL. Childhood overweight: a contextual model and recommendations for future research. Obes Rev. (2001) 2:15971. doi: 10.1046/j.1467-789x.2001.00036.x

Conflict of Interest: The authors declare that the research was conducted in the absence of any commercial or financial relationships that could be construed as a potential conflict of interest.

Copyright (c) 2021 Fan and Zhang. This is an open-access article distributed under the terms of the Creative Commons Attribution License (CC BY). The use, distribution or reproduction in other forums is permitted, provided the original author(s) and the copyright owner(s) are credited and that the original publication in this journal is cited, in accordance with accepted academic practice. No use, distribution or reproduction is permitted which does not comply with these terms. 